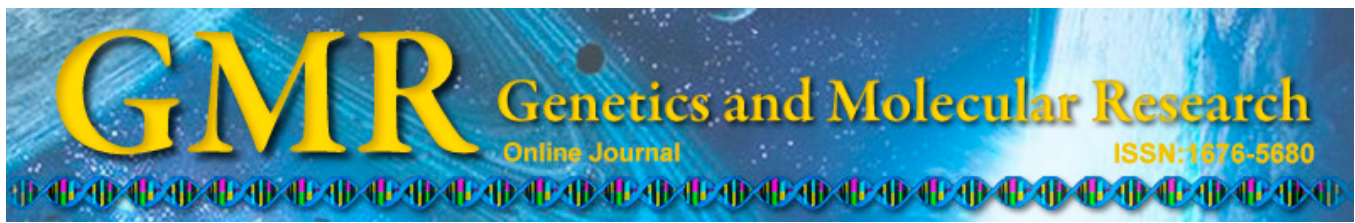

\title{
Relationship between zinc and the growth and development of young children
}

\author{
S. Gao ${ }^{1 *}$, D.N. Tu${ }^{1 *}$, H. Li ${ }^{1}$, X. Cao ${ }^{1}$, J.X. Jiang ${ }^{2}$, Y. Shi ${ }^{1}$, \\ X.Q. Zhou ${ }^{1}$ and J.B. You ${ }^{1}$ \\ ${ }^{1}$ Department of Pediatrics, \\ Woman and Child Hospital of Hubei Province, Wuhan, China \\ ${ }^{2}$ Department of Biliary-Hepatic Surgery, \\ Affiliated Hospital of Guiyang Medical College, Guiyang, China \\ *These authors contributed equally to this study. \\ Corresponding authors: X.Q. Zhou / J.B. You \\ E-mail: zhouxqdp@163.com / youjbdp@163.com
}

Genet. Mol. Res. 14 (3): 9730-9738 (2015)

Received January 7, 2015

Accepted June 24, 2015

Published August 19, 2015

DOI http://dx.doi.org/10.4238/2015.August.19.5

\begin{abstract}
The purpose of this study was to evaluate the relationship between zinc and the growth and development of young children. The parents of 8102 young children were surveyed in person by a trained surveyor using structured questionnaires. The hair zinc concentration of the children was determined using an atomic absorption spectrophotometer. The height, weight, sitting height, and head circumference of the children were measured at follow-up visits. There was a positive correlation between hair zinc concentration and adaptive developmental quotient (ADQ; $r=0.3164, \mathrm{P}=0.0272$ ) while no correlation was found between hair zinc concentration and body measurement $Z$ scores or intelligence quotient (IQ). There was a strong positive correlation between hair zinc concentration and weight-for-age $Z$ scores $(r=0.3618, P=0.0416)$ and ADQ $(r=0.2761, P=0.0387)$ in boys; there was no correlation between hair zinc concentration and body measurement $\mathrm{Z}$ scores, IQ, and ADQ in girls. In boys with normal hair zinc levels, ADQ was $9.58(\mathrm{P}=0.0392)$, higher than in boys who had
\end{abstract}


zinc-deficient hair. In girls with normal hair zinc levels, ADQ was 2.52 $(\mathrm{P}=0.0296)$, lower than in girls with zinc-deficient hair. In conclusion, there is no significant correlation between hair zinc levels and IQ or Z scores for all body measurements in young children.

Key words: Zinc; Young children; Growth; Child development

\section{INTRODUCTION}

Zinc is an essential microelement for the human body. It contributes to the composition of multiple enzymes and is indispensable to enzymatic activity. It is involved in the synthesis of proteins and nucleic acids, and in cell growth, division, and differentiation (O'Loughlin and O'Donnell, 2011). Zinc is also important for the structure and function of the nervous system. It is particularly important for children during their growth and development. Zinc deficiency in children can lead to retardation of growth and development, hypophysis adjustment dysfunction, and inappetence (Alves et al., 2012).

Hair zinc concentration is an index for zinc nutrition status in vivo and can reflect zinc accumulation and metabolism over a certain period (Heidemann et al., 2013). Prodam and Aimaretti's research (2013) has shown that the hair zinc concentration in anorectic children is significantly lower than that of healthy children and that hair zinc concentration is positively correlated with dietary zinc intake and erythrocyte zinc concentration. A low concentration of hair zinc indicates that the human body is suffering from chronic zinc malnutrition. Gogia and Sachdev's research (2012) has found that hair zinc concentration in children with stunted growth is lower than that in normal children. However, results obtained by Kamer et al. (2012) have indicated that there is no correlation between hair zinc concentration and whole blood zinc. A further study on 520 young children aged 3-8 years by Ekbote et al. (2013) has found that there is no correlation between hair zinc concentration and stature or weight. Our study aims to determine the relationship between hair zinc concentration and the growth and development of young children by measuring their hair zinc concentration, physical development, intelligence, and behavior adaptation capabilities.

\section{MATERIAL AND METHODS}

\section{Research subjects}

We surveyed 8102 children from 13 provinces or cities throughout the country, including Beijing City, Shanghai City, and Jiangsu Province, of whom 4154 were boys and 3948 were girls. There were 4206 children aged 3-4 years and 3896 aged 4-5 years. All children were from a follow-up study on the effects of zinc replenishment during the gestation period on the growth and development of young children. None of the children had a history of severe chronic disease.

\section{Questionnaire}

The children's parents were surveyed in person by trained surveyors using structured questionnaires. The main content of the structured questionnaire included questions on the 
general demographic characteristics of the children's parents (including age, educational level, occupation, and smoking and drinking habits), household income, gestation and delivery conditions [including information on previous pregnancy, disease during the gestation period, nutritional status, severity of pregnancy reactions, adverse physical and chemical factors (such as exposure to $\mathrm{X}$ rays), medications, and antenatal training], and potential confounding factors such as breast feeding, complementary foods, and early education of children from birth to approximately 3 years of age (Ghanizadeh and Berk, 2013).

\section{Measurement of zinc levels in children}

Hair samples $(0.5-1 \mathrm{~g})$ were collected at the site of posterior occipitalia adjacent to the scalp with a pair of stainless steel scissors. Hair zinc concentration was measured with an atomic absorption spectrophotometer model 4530F (Precision Scientific Apparatus Co., Ltd., Shanghai, China,) after washing, drying, and digestion of hair samples. The recovery rate of zinc was $98.8 \%$.

\section{Determination of body measurements, intelligence quotient (IQ), and adaptation development quotient (ADQ) of children}

The stature, body weight, sitting height, and head circumference of the children were measured at follow-up visits. Body weight was accurate to $50 \mathrm{~g}$ and stature and sitting height were accurate to $0.5 \mathrm{~cm}$. Body mass index (BMI) was calculated based on body weight and stature $\left[\mathrm{BMI}=\right.$ body weight $(\mathrm{kg}) /$ stature $\left.(\mathrm{m})^{2}\right]$. Head circumference was measured with a measuring tape and was accurate to $0.1 \mathrm{~cm}$. All measuring tools were calibrated against standard measuring tools. Children's IQ was determined using the Binet and Raven Intelligence Scales (Qian et al., 2005). Children's ADQ was assessed using the behavioral adaptation scale (Ghanizadeh and Berk, 2013).

\section{Statistical analysis}

In consideration of the effects of children's age and gender on body measurements, stature, body weight, head circumference, and sitting height were standardized and converted into $\mathrm{Z}$ scores $(\mathrm{Z}$ score $=$ actual measured value - reference value median (or arithmetic average) / standard deviation of the reference value). $Z$ scores of measured data were calculated in accordance with WHO Standardized Reference Values for Children's Body Measurement (1993) to eliminate the effects of the children's age and gender in terms of comparability in body measurement indexes. The relationship between children's hair zinc concentration and their growth and development was analyzed by a simple correlation; body measurement $\mathrm{Z}$ scores, IQ, and ADQ of children in the normal hair zinc group and deficient hair zinc group were analyzed using the $t$-test. A multiple-factor analysis was conducted for the growth and development of children in the normal hair zinc group and deficient hair zinc group using a general linear model (GLM). All data were analyzed using SPSS 15.0 (IBM, USA) and a significance level of $\mathrm{P}=0.05$ was considered to be significant. $\mathrm{Z}$ values were calculated and converted using Epi-Info 2002 (CDC, USA) and Office Excel 2003 (Microsoft, USA). 


\section{RESULTS}

\section{Concentrations of hair zinc in children}

The hair zinc concentration of the 8102 children ranged 32.62-146.73 $\mu \mathrm{g} / \mathrm{g}$, with an mean of $81.53 \pm 32.66 \mu \mathrm{g} / \mathrm{g}$. The mean hair zinc concentration in boys was $84.25 \pm 34.16 \mu \mathrm{g} / \mathrm{g}$ and in girls $76.37 \pm 29.46 \mu \mathrm{g} / \mathrm{g}$. The difference was not statistically significant. The hair zinc concentration in children below 4 years of age was $86.37 \pm 33.41 \mu \mathrm{g} / \mathrm{g}$ and in children above 4 years of age it was $72.64 \pm 30.81 \mu \mathrm{g} / \mathrm{g}$; this difference was not statistically significant either. The tenth percentile $\left(\mathrm{P}_{10}\right)$ of hair zinc concentration in children of each age group served as the threshold value. A value below $\mathrm{P}_{10}$ indicated hair zinc deficiency and a value equal to or above $\mathrm{P}_{10}$ indicated normal hair zinc. Of the 8102 children, a total of $1253(15.46 \%)$ had hair zinc deficiency. There was no statistical difference in the hair zinc deficiency rate between boys and girls or between the different age groups (Table 1).

Table 1. Distribution of hair zinc in children by gender and age.
\begin{tabular}{lcccr}
\hline & $P_{10}(\mu \mathrm{g} / \mathrm{g})$ & Cases of hair zinc deficiency (\%) & Cases of normal hair zinc (\%) & Total \\
\hline Gender & & & & \\
Boys & - & $592(14.25 \%)$ & $3562(85.75 \%)$ & 4154 \\
Girls & - & $661(16.74 \%)$ & $3287(83.26 \%)$ & 3948 \\
Age (years) & 47.5 & $647(15.38 \%)$ & $3559(84.62 \%)$ & 4206 \\
$3-4$ & 41.3 & $606(15.55 \%)$ & $3290(84.45 \%)$ & 3896 \\
$4-5$ & &
\end{tabular}

\section{Physical, intellectual, and behavioral development of children}

Body measurement results showed a low rate of maldevelopment in children. A Z score below -2 was defined as maldevelopment. The maldevelopment rate for stature for age, BMI, head circumference, and weight for stature ranged from 1 to $3.57 \%$, consistent with the probability of the standard normal distribution (a Z score below -2 accounted for $2.16 \%$ under standard normal distribution conditions). The IQ and ADQ of all children were higher than 75 , i.e., there were no children with mild deficiency in intelligence or adaptive behavioral competence according to these tests. An IQ below 80 and ADQ below 85 are deemed to reflect maldevelopment in terms of intelligence and adaptive behavioral competence, respectively; the maldevelopment rates for IQ and ADQ were 3.27 and 3.12\%, respectively (Table 2).

\begin{tabular}{|c|c|c|c|c|c|}
\hline \multirow[t]{2}{*}{ Development measurement } & \multirow[t]{2}{*}{ Number of cases } & \multirow[t]{2}{*}{ Mean } & \multirow[t]{2}{*}{ Standard deviation } & \multicolumn{2}{|c|}{ Maldevelopment } \\
\hline & & & & (Number of cases) & Percentage $(\%)$ \\
\hline \multicolumn{6}{|l|}{ Body measurement $Z$ score } \\
\hline Stature & 8073 & -0.68 & 0.36 & 288 & 3.57 \\
\hline Body weight & 8066 & -0.55 & 0.32 & 272 & 3.37 \\
\hline Weight for stature & 8061 & 0.26 & 0.73 & 256 & 3.18 \\
\hline BMI & 8078 & 0.11 & 0.86 & 245 & 3.03 \\
\hline Head circumference & 8063 & 0.06 & 0.91 & 261 & 3.24 \\
\hline IQ & 8054 & 95.16 & 11.73 & 263 & 3.27 \\
\hline ADQ & 8066 & 108.27 & 16.24 & 252 & 3.12 \\
\hline
\end{tabular}

$\mathrm{BMI}=$ body mass index; IQ = intelligence quotient; $\mathrm{ADQ}=$ adaptive developmental quotient. 


\section{Correlation between hair zinc and physique, intelligence, and behavioral adaptation} development in children

Correlation analyses were conducted for hair zinc and body measurement $\mathrm{Z}$ scores, IQ, and ADQ of children. There was a positive correlation between hair zinc and ADQ $(r=$ $0.3164, \mathrm{P}=0.0272$ ); however, there was no correlation between hair zinc and the body measurement Z scores or IQ of children (Table 3).

\begin{tabular}{lcc}
\hline \multicolumn{2}{|c}{ Table 3. Correlation between hair zinc and body measurement Z scores, IQ, and ADQ. } \\
\hline Development measurement & Correlation coefficient & P value \\
\hline Body measurement Z score & & 0.6245 \\
Stature & 0.0834 & 0.6832 \\
Body weight & 0.0512 & 0.8641 \\
Weight for stature & 0.0161 & 0.9214 \\
BMI & 0.0113 & 0.7855 \\
Head circumference & 0.0436 & 0.7361 \\
IQ & 0.0485 & 0.0272 \\
ADQ & 0.3164 & \\
\hline
\end{tabular}

$\mathrm{BMI}=$ body mass index; IQ = intelligence quotient; $\mathrm{ADQ}=$ adaptive developmental quotient.

In terms of gender, in boys there was a high correlation between hair zinc and the weight-for-age $\mathrm{Z}$ scores (WAZ, $\mathrm{r}=0.3618, \mathrm{P}=0.0416)$ and ADQ $(\mathrm{r}=0.2761, \mathrm{P}=0.0387)$ and no correlation between hair zinc and other body measurement $Z$ scores or IQ; in girls, there was no correlation between hair zinc and any of the body measurement $Z$ scores, IQ, or ADQ (Figure 1A-D). There was a positive correlation between hair zinc and ADQ in children under 4 years of age $(r=0.2536, P=0.0438)$ while there was no correlation with any of the body measurement $\mathrm{Z}$ scores and IQ. There was a negative correlation between hair zinc and the WAZ in children at and above 4 years of age $(r=-0.3016, P=0.0292)$, while there was no correlation between hair zinc and other body measurement $\mathrm{Z}$ scores, IQ, or ADQ.
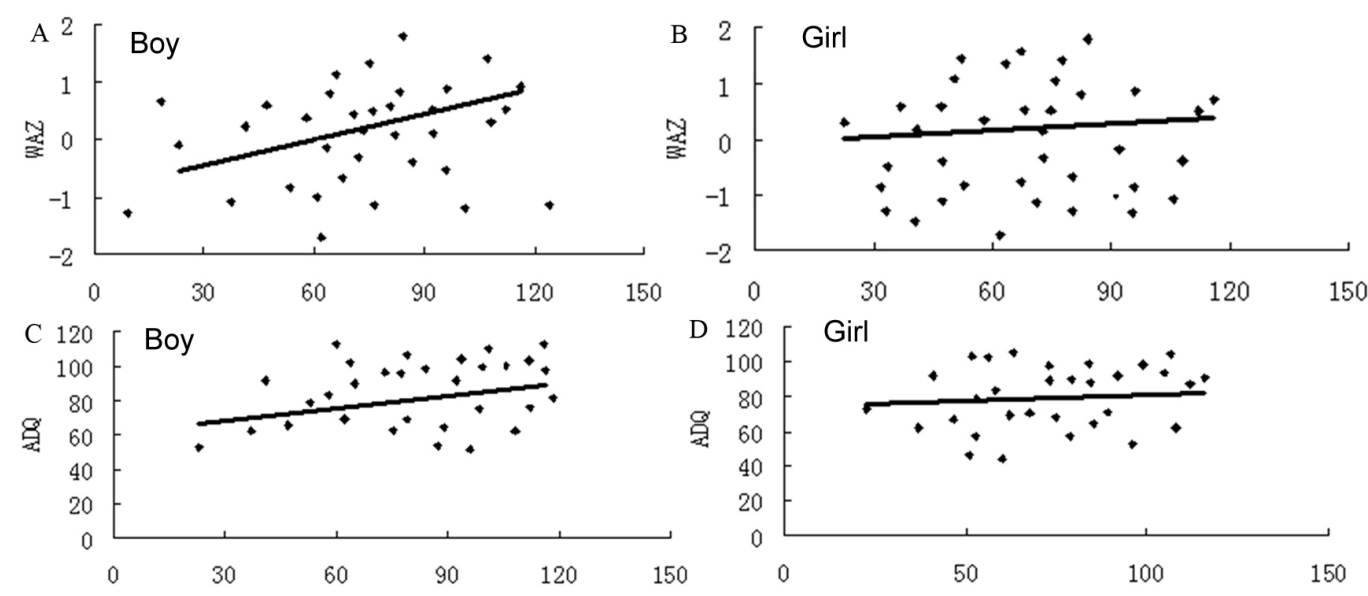

Figure 1. Correlation between weight-for-age Z score (WAZ) in boys (A), WAZ in girls (B), adaptive developmental quotient (ADQ) in boys $(\mathbf{C})$, and ADQ in girls $(\mathbf{D})$ and hair zinc concentration $(\mu \mathrm{g} / \mathrm{g})$. 


\section{Effects of hair zinc on physique, intelligence, and behavioral adaptation development of children}

Children were divided into a normal and deficient hair zinc group with hair zinc $\mathrm{P}_{10}$ serving as the threshold value. Comparisons were made for body measurement $\mathrm{Z}$ scores, IQ, and ADQ between the two groups and the differences were not statistically significant ( $t$-test). In boys, ADQ in the normal hair zinc group was $9.58(\mathrm{P}=0.0392)$, higher than that for the deficient group. In girls, ADQ in the normal hair zinc group was $2.52(\mathrm{P}=0.0296)$, lower than that for the deficient group. After adjustment for zinc supplementation during pregnancy, family economic status, parents' ages, and education levels using the GLM process, the ADQ of normal hair zinc group was 34 for boys, higher than that of the deficient group. There was still no statistical difference in ADQ between the groups for girls. There were no statistical differences in body measurement $\mathrm{Z}$ scores and IQ between the normal and deficient groups in either boys or girls. When compared by age, there were no statistically significant differences in body measurement $\mathrm{Z}$ scores, IQ, or ADQ between the normal and deficient groups (Table 4).

\begin{tabular}{|c|c|c|c|c|c|c|}
\hline \multirow[t]{2}{*}{ Development measurement } & \multicolumn{2}{|c|}{ Boys } & \multicolumn{2}{|c|}{ Girls } & \multicolumn{2}{|c|}{ Total } \\
\hline & Difference value & $95 \% \mathrm{CI}$ & Difference value & $95 \% \mathrm{CI}$ & Difference value & $95 \% \mathrm{CI}$ \\
\hline \multicolumn{7}{|l|}{ Body measurement $Z$ score } \\
\hline Stature & 0.72 & $-0.35-1.67$ & -0.37 & $-0.93-0.44$ & 0.12 & $-0.36-0.64$ \\
\hline Body weight & 0.66 & $-0.26-1.53$ & -0.52 & $-1.26-0.34$ & -0.14 & $-0.61-0.53$ \\
\hline Weight for stature & 0.53 & $-0.29-1.26$ & -0.24 & $-1.13-0.65$ & -0.08 & $-0.78-0.71$ \\
\hline BMI & 0.34 & $-0.32-1.36$ & -0.46 & $-0.81-0.73$ & -0.23 & $-0.82-0.45$ \\
\hline Head circumference & 0.46 & $-0.16-1.37$ & 0.27 & $-0.76-1.15$ & 0.27 & $-0.42-1.17$ \\
\hline IQ & -0.62 & $-7.24-8.45$ & -2.16 & $-6.75-5.61$ & -1.82 & $-4.67-3.64$ \\
\hline ADQ & 9.58 & $0.73-19.24$ & -2.52 & $-11.29-10.65$ & 2.96 & $-3.89-9.21$ \\
\hline
\end{tabular}

Difference value $=$ the mean of the normal hair zinc group - the mean of the hair zinc deficiency group; $95 \% \mathrm{CI}$ is the confidence interval for the difference value between the normal hair zinc group and the deficient hair zinc group. $\mathrm{BMI}=$ body mass index; IQ = intelligence quotient; $\mathrm{ADQ}=$ adaptive developmental quotient.

\section{DISCUSSION}

As an essential microelement in the human body, zinc is involved in many important physiological functions. It is particularly indispensable for children during the growth period. Many studies have shown that zinc plays a role in promoting physical growth and the development of intelligence in children (Ozbek and Akman, 2012). The role of zinc in promoting growth and development during infancy, and even during the fetal period, has been deciphered. In this study, the hair zinc concentration, physique, intelligence, and behavioral adaptation of 8102 children were measured. The results show a positive correlation between hair zinc and ADQ in boys, as demonstrated by correlation analysis and the comparison of ADQ between the normal and deficient groups. There was no significant correlation between hair zinc and any of the body measurement $Z$ scores or IQ in either boys or girls.

When zinc intake is insufficient or zinc malnutrition occurs as a result of other causes, many physiological processes involving zinc will be affected to different extents. Various symptoms can occur when the compensation capability of the human body is exceeded (Wojciak 
et al., 2013). Deficiency generally manifests through effects on growth and development during infancy, for example no or slow increases in height and weight, and also through retardation in the development of intelligence and a low intelligence quotient in children due to effects on brain development (Moran et al., 2012). A great deal of research has shown that there is a correlation between in vivo zinc levels and stature, body weight, or intelligence of children (Liu et al., 2012). Zinc supplementation for children with zinc deficiency can improve their growth and development rates as well as their stature, body weight, and intelligence. A randomized double-blind control study on 1625 African-American pregnant women with a low zinc nutritional status, conducted by Razi et al. (2012), indicates that supplementation of 25 $\mathrm{mg}$ /day zinc can significantly increase the birth weight of newborns, particularly for pregnant women with a BMI less than $24 \mathrm{~kg} / \mathrm{m}^{2}$. Elizabeth (2011) has found that oral administration of $20 \mathrm{mg}$ zinc to pregnant women who had previously given birth to small for gestational age babies can reduce the incidence of intrauterine growth retardation.

Hair is one of the routes through which zinc is excreted from the human body. The concentration of hair zinc increases when in vivo zinc is sufficient or surplus; however, zinc excretion, e.g., through hair, does not necessarily correlate with zinc in the body due to the requirements for maintaining homeostasis when zinc levels are insufficient or marginally deficient (Amalrajan et al., 2012). According to the literature, hair zinc concentration is affected by multiple factors. Although zinc intake will be insufficient when severe malnutrition occurs, hair zinc concentrations can be significantly higher than those of the healthy people due to the low growth rate of hair (Estakhri et al., 2011). An examination of zinc supplementation in 100 children with serum zinc lower than $13.0 \mu \mathrm{M}$ and 100 children with hair zinc lower than 13.0 $\mu \mathrm{g} / \mathrm{g}$ indicated that mean serum zinc rose 6 months after zinc supplementation; however, in contrast, hair zinc declined (Wang et al., 2013). Thus, this method may be insufficient to assess the nutritional status of zinc in the body.

No correlation was observed between hair zinc and body measurement $Z$ scores or intelligence. Shah et al. (2013) have estimated infant requirements for zinc based on zinc retention and loss in urine and sweat and observed that the demand for zinc in female infants is approximately $8 \%$ lower than in male infants. This difference in zinc metabolism may contribute to the sex difference in the correlation between hair zinc and ADQ seen here (Liu et al., 2012).

At present, a number of research studies have suggested that zinc plays a role in promoting growth and development; however, there are conflicting results regarding these relationships in relation to the different indexes used. To date, the indexes used to assess zinc status include blood zinc (plasma zinc, serum zinc, and whole blood zinc), hair zinc, and urinary zinc. Hair zinc has long been used due to ease of collection and storage, convenient testing, and availability of duplicate samples for testing. However, we have seen no correlation between hair zinc and body measurement $\mathrm{Z}$ scores or intelligence in the children we studied, possibly due to the fact that hair zinc does not accurately reflect zinc status in the body.

A study by Das et al. (2012) has shown that parenting can promote the development of children's adaptive behavior; harmonious family relationships, and a healthy social environment can contribute to improvements in children's adaptive behavior, as can a mother's age and health status. A study by Lazzerini and Ronfani (2012) suggests that fathers' education levels and family educational methods significantly affect children's adaptive behaviors. These social and family factors may weaken the biological relationship between nutrition and the development of adaptive behaviors. Taverna et al. (2012) have also opined that the effect of family environments and parenting on the development of children's adaptive behaviors is 
as important as nutritional status. This may be one of the reasons for the lack of correlation between hair zinc concentration and ADQ in girls. In addition, the different correlations between adaptation development and zinc between boys and girls may be associated with differences in zinc metabolism in vivo. Zinc metabolism differs between genders from infancy.

The correlation coefficient for ADQ and hair zinc concentration was 0.3164 , indicating a definite correlation between children's behavior adaptation and zinc. Other studies have also reported such a relationship, e.g., research by Morales-Ruán et al. (2012) indicates that as malnutrition becomes more severe in children, ADQ values also decrease. A study by Wang et al. (2012) also indicates that nutritional status is associated with ADQ in children. Malnourished children have defective social adaptive capacity, which manifests as learning disability, reading disability, dysgraphia, short attention spans, and slow responses (Wang et al., 2012). However, in this study, based on the correlation coefficient for ADQ and hair zinc concentration, this relationship was not significant. This may be due to the fact that many factors influence ADQ and factors such as family environment and family educational methods may have a greater impact. Indeed, it is also possible that the gender difference is preliminary result and requires further study for clarification.

\title{
ACKNOWLEDGMENTS
}

\author{
Research supported by the Natural Science Foundation of China (\#81160311).
}

\section{REFERENCES}

Alves CX, Vale SH, Dantas MM, Maia AA, et al. (2012). Positive effects of zinc supplementation on growth, GH, IGF1, and IGFBP3 in eutrophic children. J. Pediatr. Endocrinol. Metab. 25: 881-887.

Amalrajan V, Thankachan P, Selvam S and Kurpad A (2012). Effect of wheat flour fortified with sodium iron EDTA on urinary zinc excretion in school-aged children. Food Nutr. Bull. 33: 177-179.

Das RR, Singh M and Shafiq N (2012). Short-term therapeutic role of zinc in children $<5$ years of age hospitalised for severe acute lower respiratory tract infection. Paediatr. Respir. Rev. 13: 184-191.

Ekbote V, Khadilkar A, Chiplonkar S, Mughal Z, et al. (2013). Enhanced effect of zinc and calcium supplementation on bone status in growth hormone-deficient children treated with growth hormone: a pilot randomized controlled trial. Endocrine 43: 686-695.

Elizabeth KE (2011). Iron and zinc deficiency in children. Indian Pediatr. 48: 741-742.

Estakhri M, Djazayery A, Eshraghian M, Majdzadeh R, et al. (2011). Serum zinc levels in children and adolescents with type-1 diabetes mellitus. Iranian J. Public Health 40: 83-88.

Ghanizadeh A and Berk M (2013). Zinc for treating of children and adolescents with attention-deficit hyperactivity disorder: a systematic review of randomized controlled clinical trials. Eur. J. Clin. Nutr. 67: 122-124.

Gogia S and Sachdev HS (2012). Zinc supplementation for mental and motor development in children. Cochrane Database Syst. Rev. 12: CD007991.

Heidemann SM, Holubkov R, Meert KL, Dean JM, et al. (2013). Baseline serum concentrations of zinc, selenium, and prolactin in critically ill children. Pediatr. Crit. Care Med. 14: 202-206.

Kamer B, Wąsowicz W, Pyziak K, Kamer-Bartosińska A, et al. (2012). Role of selenium and zinc in the pathogenesis of food allergy in infants and young children. Arch. Med. Sci. 8: 1083-1088.

Lazzerini M and Ronfani L (2012). Oral zinc for treating diarrhoea in children. Cochrane Database Syst. Rev. 6: CD005436.

Liu J, Yuan E, Zhang Z, Jia L, et al. (2012). Age- and sex-specific reference intervals for blood copper, zinc, calcium, magnesium, iron, lead, and cadmium in infants and children. Clin. Biochem. 45: 416-419.

Morales-Ruán Mdel C, Villalpando S, García-Guerra A, Shamah-Levy T, et al. (2012). Iron, zinc, copper and magnesium nutritional status in Mexican children aged 1 to 11 years. Salud Publica Mex. 54: 125-134.

Moran VH, Stammers AL, Medina MW, Patel S, et al. (2012). The relationship between zinc intake and serum/plasma zinc concentration in children: a systematic review and dose-response meta-analysis. Nutrients 4: 841-858. 
O'Loughlin A and O'Donnell BF (2011). Zinc deficiency in a breast-fed baby. Ir. Med. J. 104: 285.

Ozbek N and Akman S (2012). A slurry sampling method for the determination of iron and zinc in baby food by flame atomic absorption spectrometry. Food Addit. Contam. Part A Chem. Anal. Control Expo. Risk Assess. 29: 208-216.

Prodam F and Aimaretti G (2013). Could zinc supplementation improve bone status in growth hormone (GH) deficient children? Endocrine 43: 467-468.

Qian M, Wang D, Watkins WE, Gebski V, et al. (2005) The effects of iodine on intelligence in children: a meta-analysis of studies conducted in China. Asia Pac. J. Clin. Nutr. 14: 32-42.

Razi CH, Akelma AZ, Akin O, Kocak M, et al. (2012). Hair zinc and selenium levels in children with recurrent wheezing. Pediatr. Pulmonol. 47: 1185-1191.

Shah UH, Abu-Shaheen AK, Malik MA, Alam S, et al. (2013). The efficacy of zinc supplementation in young children with acute lower respiratory infections: a randomized double-blind controlled trial. Clin. Nutr. 32: 193-199.

Taverna L, Bornstein MH, Putnick DL, and Axia G (2012). Adaptive behaviors in young children: A unique cultural comparison in Italy. J. Cross Cult. Psychol. 42: 445-465.

Wojciak RW, Mojs E, Stanislawska-Kubiak M and Samborski W (2013). The serum zinc, copper, iron, and chromium concentrations in epileptic children. Epilepsy Res. 104: 40-44.

Wang G, Feng X, Yu X, Xu X, et al. (2013). Prognostic value of blood zinc, iron, and copper levels in critically ill Children with pediatric risk of mortality score III. Biol. Trace Elem. Res. 152: 300-304.

Wang H1, Shi H, Chang L, Zhang X, et al. (2012). Association of blood lead with calcium, iron, zinc and hemoglobin in children aged 0-7 years: a large population-based study. Biol. Trace Elem. Res. 149: 143-147. 